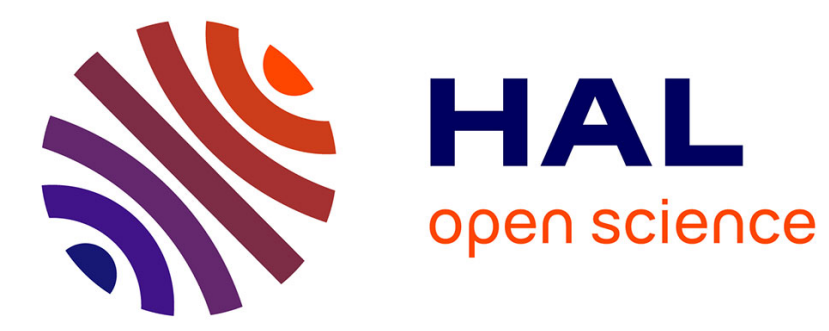

\title{
Thermal analysis by DSC of Phase Change Materials, study of the damage effect
}

Sara Drissi, Anissa Eddhahak, Sabine Caré, Jamel Neji

\section{To cite this version:}

Sara Drissi, Anissa Eddhahak, Sabine Caré, Jamel Neji. Thermal analysis by DSC of Phase Change Materials, study of the damage effect. Journal of Building Engineering, 2015, 1, pp.13-19. 10.1016/j.jobe.2015.01.001 . hal-01174646

\section{HAL Id: hal-01174646 https://hal.science/hal-01174646}

Submitted on 9 Jul 2015

HAL is a multi-disciplinary open access archive for the deposit and dissemination of scientific research documents, whether they are published or not. The documents may come from teaching and research institutions in France or abroad, or from public or private research centers.
L'archive ouverte pluridisciplinaire HAL, est destinée au dépôt et à la diffusion de documents scientifiques de niveau recherche, publiés ou non, émanant des établissements d'enseignement et de recherche français ou étrangers, des laboratoires publics ou privés. 


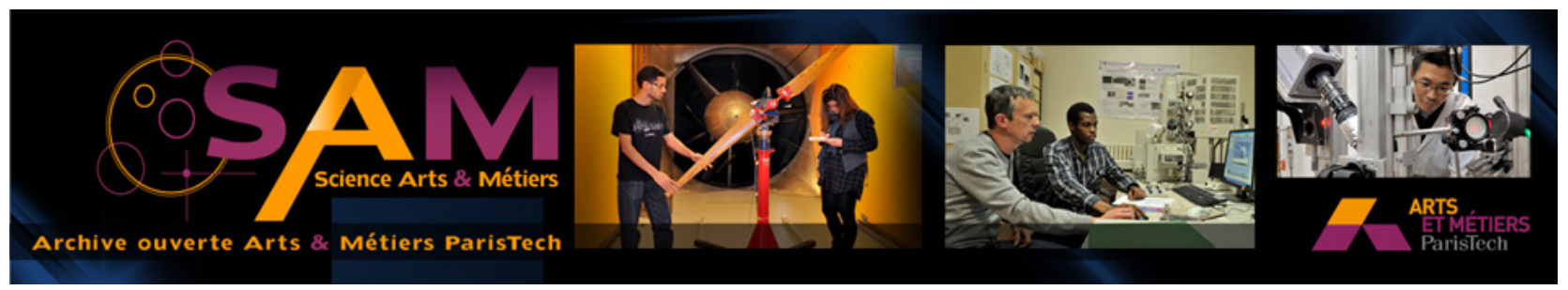

Science Arts \& Métiers (SAM)

is an open access repository that collects the work of Arts et Métiers ParisTech researchers and makes it freely available over the web where possible.

This is an author-deposited version published in: http://sam.ensam.eu

Handle ID: .http://hdl.handle.net/10985/9744

\section{To cite this version :}

Sara DRISSI, Anissa EDDHAHAK, Sabine CARE, Jamel NEJI - Thermal analysis by DSC of Phase Change Materials, study of the damage effect - Journal of Building Engineering - Vol. 1, p.13-19- 2015 


\title{
Thermal analysis by DSC of Phase Change Materials, study of the damage effect
}

\author{
Sarra Drissi ${ }^{\mathrm{a}, \mathrm{b}, \mathrm{c}}$, Anissa Eddhahak ${ }^{\mathrm{d}, *}$, Sabine Caré ${ }^{\mathrm{b}}$, Jamel Neji ${ }^{\mathrm{c}}$ \\ a Université Paris-Est-Institut de recherche en constructibilité, ESTP, 28 Avenue du Président Wilson, 94234 Cachan cedex, France \\ ${ }^{\mathrm{b}}$ Université Paris-Est, Laboratoire Navier (UMR 8205), CNRS, ENPC, IFSTTAR, 6-8 Av. Blaise Pascal, 77455 Marne La Vallée, France \\ ' Université Tunis El Manar-Laboratoire de Matériaux, d'Optimisation et d'Energie pour la Durabilité, \\ LAMOED Ecole Nationale d'Ingénieurs de Tunis, BP 37, Le belvédère 1002, Tunis \\ d Laboratory PIMM, CNRS UMR 8006, Arts et Métiers ParisTech, 151 bd de l'Hôpital, 75013 Paris, France.
}

Keywords:

Phase Change Materials (PCMs)

Thermodynamic properties

Differential scanning calorimetry (DSC)

Heat capacity

Damage

\begin{abstract}
A B S T R A C T
This paper deals with an experimental study of Phase Change Materials (PCMs) by DSC and focuses particularly on the influence of PCMs damage on their thermodynamic properties. First, different series of tests were performed on non-damaged PCMs (reference) using different masses and heating rates in order to optimize the choice of the experimental parameters used in DSC test. Accordingly, the specific heats at solid, liquid phases and the latent heats of PCMs were obtained. In addition, a fast approximate approach was suggested for the determination of the heat capacity of PCMs from a direct exploitation of the heat flux curves obtained by scanning PCMs at different heating rates. Finally, damaged PCMs were investigated and their thermal properties (specific heat and phase change enthalpy) were compared to the reference PCMs. It was shown from the obtained results that low heating rates are more suitable for PCMs scanning during DSC measurements in order to ensure a thermodynamic equilibrium within the sample. Furthermore, the results highlighted that damage of PCMs can lead to the loss of their specific heat capacity of about $28 \%$ compared to the non-damaged PCMs.
\end{abstract}

\section{Introduction}

During recent years, the total world energy consumption and the associated $\mathrm{CO}_{2}$ emissions in commercial and residential buildings are rising dramatically [1]. To cope-up with this hazardous situation, the solar Thermal-Energy Storage (TES) in building structures has shown to be a promising solution aiming to the reduction of the energy consumption and the improvement of the indoor thermal conditions [2]. One of the options for the achievement of the TES technology is the use of Phase Change Materials (PCMs) which have the ability to store and release a high amount of energy by latent heat [3]. Typically classified into three families: organic, inorganic and eutectic [4,5], PCMs have shown good stability and compatibility with the cement-based construction materials [6], thereby offering a rational and intelligent management of the energy use in buildings. From apart the environmental and economical benefits of PCMs technology, the thermal comfort of the occupants can be significantly improved [7,8] in both domestic and commercial buildings by the decreasing of the

\footnotetext{
* Corresponding author. Tel.: +33699247666.

E-mail addresses: sdrissi@adm.estp.fr (S. Drissi), anissa.EDDHAHAK@ensam.eu (A. Eddhahak), sabine.care@ifsttar.fr (S. Caré), jamel.neji@enit.rnu.tn (J. Neji).
}

indoor temperature on the one hand, and the smoothing of the thermal fluctuations on the other one [9].

PCMs can be microencapsulated in a polymer shell in order to prevent the leakage of the core material during their melting. The microencapsulation technique is also advantageous because it provides an exchange surface between PCMs and the surrounding material contributing therefore to the improvement of the thermal transfer conditions. The morphology of microcapsules depends mainly on the core material and the deposition process of the shell. There are three basic morphologies of microcapsules: Mononuclear, Polynuclear and matrix-encapsulation. In addition to these morphologies, microcapsules can also be monocuclear with multiple shells, or they may form clusters of microcapsules. For further information regarding PCMs encapsulation technique, the readers could consult the detailed review papers of $[10,11]$ where some investigations on microencapsulated PCMs for thermal energy storage in building applications are described.

So far, many researchers have focused on the use of PCMs in building sector and their association with the construction materials (concrete, gypsum...) in order to enhance the overall thermal inertia of the structure. A particular interest has been paid to organic PCMs, for instance, which present several attractive properties making them good candidates for incorporation in the building materials. Some of their advantages can be their 


\begin{tabular}{|c|c|c|c|}
\hline \multicolumn{2}{|c|}{ Nomenclature } & $\Phi$ & Heat fluxes (W) \\
\hline \multicolumn{2}{|c|}{ Latin letters } & $\Delta H$ & Latent heat $(\mathrm{J} / \mathrm{kg})$ \\
\hline$C p$ & Specific heat capacity (J/kg K) & \multicolumn{2}{|c|}{ Superscripts } \\
\hline$k$ & Calibration coefficient & & \\
\hline$m$ & Mass $(\mathrm{kg})$ & $r$ & reference \\
\hline$R_{f}$ & Thermal resistance of furnace $(\mathrm{K} / \mathrm{W})$ & $s$ & sample \\
\hline$T$ & Temperature $(\mathrm{K})$ & & \\
\hline$t$ & Time $(s)$ & \multicolumn{2}{|c|}{ Subscripts } \\
\hline \multicolumn{2}{|c|}{ Greek letters } & $m$ & $\begin{array}{l}\text { melting } \\
\text { solid }\end{array}$ \\
\hline$\beta$ & Heating/cooling rate $(\mathrm{K} / \mathrm{min})$ & $l$ & liquid \\
\hline
\end{tabular}

availability in a large temperature range, their chemical stability, the little super-cooling phenomenon and phase segregation, etc. Meshgin et al. [12] focused on the study of the thermal and mechanical properties of concrete modified with PCMs. Later on, Hunger et al., [13] used microencapsulated PCMs in selfcompacting concrete and studied their effect on the concrete behavior. Recently, Eddhahak et al. [14] worked on the effect of PCMs when incorporated in cement Portland concrete and used a multi-scale approach to evaluate the thermal properties of the PCM-concrete. The main conclusions drawn from these works can be summarized in the improvement of the heat storage capacity of the PCM-concrete on the one hand, and the loss of its mechanical strength with the addition of PCMs on the other one. More recently, it was highlighted in a previous work [15] some reasons which could explain the decrease of the mechanical strength of concrete with PCMs by the investigation of the cement hydration reaction track. Although the numerous studies and the extensive literature focused on PCMs, many queries are still raised regarding this technology and its sustainability from an energy efficiency point of view especially when integrated in the construction material. In our sense, this confusion can be associated to the fact that the PCMs characteristics themselves are not sufficiently well controlled because of the lack of specific standards and methods for the tabulation and exploitation of results derived from experiments $[16,17]$. For instance, the determination of the thermodynamic properties of PCMs is not straightforward as it can be imagined, since typical heating and cooling rates used in DSC measurements (5-10 K/min) are in anyway compatible for PCMs case and much attention has to be paid to the test parametric control in order to avoid wrong estimations of their thermal characteristics [18]. More precisely, the influence of the heating rate taking into account the investigated volume has been studied in very few papers but more research is needed [19]. Thus, in order to control the performance of the PCM-based material, the inherent properties of PCMs themselves shall be well known with sufficient accuracy. In this context, many researches focused on the investigation of the thermal properties of PCMs. Jin et al. [20], for instance, suggested a new experimental method by DSC called the partially-melted DSC method, for the determination of the melting temperature range of PCMs. However, the estimation of the starting melting temperature was not accurately determined by the authors. Barreneche et al. [21] focused on the comparison of dynamic and step DSC modes for the investigation of organic and inorganic PCMs. They concluded that both methods can be suitable for paraffin materials and recommended a slower scanning rate for their study. Nevertheless, no quantitative information on the optimal sample mass was given in their study.

All of these works focused on the study of PCMs properties in their natural state but to our knowledge, no research has been undertaken to study the PCMs in their modified or damaged state in relation with the messy aspects of processing. Namely, it shall be emphasized that PCMs can be subjected to damage when incorporated in the cementitious mixture. Furthermore, it was revealed by SEM observations of PCM-concrete in a previous research [13] that the concrete manufacture can lead to the capsules deterioration especially when PCMs are introduced at the first stage of the mixing process. It shall be emphasized that PCMs damage can exhibit several drawbacks since their deterioration may result in the breakage of the polymer shell capsules and therefore the leakage of the paraffin active material in the surrounding matrix. Accordingly, both energy efficiency and stability of damaged PCMs and their effective contribution to the improvement of the thermal characteristics of the construction material are questioned. In order to determine the effect of PCM damage on their thermodynamic properties, it is first necessary to assess reliable and accurate experimental methods for their investigation. This means that the experimental parameters related to the experimental configuration have to be properly controlled.

In this context, the aim of the present research is twofold

(i) To perform first a thermal analysis of PCMs by DSC in order to identify and optimize the set of experimental parameters to be used for PCMs testing by DSC; and

(ii) to draw conclusions from the results DSC parameters optimization in order to provide qualitative and quantitative information as regards the influence of PCMs damage on their thermodynamic properties.

\section{Materials and methods}

\subsection{PCMs description}

Organic paraffinic PCMs called Micronal ${ }^{\circledR}$ DS 5038X in powder form (from BASF) are considered in this study. They are composed of a mixture of paraffin waxes with a melting point of $25^{\circ} \mathrm{C}$ and a phase change enthalpy of $100 \mathrm{~kJ} / \mathrm{kg}$ according to the manufacturer. The paraffin is microencapsulated in a plastic layer of polymethyl methacrylate (PMMA). The microencapsulation technique is used to facilitate the incorporation of the phase change material into the construction material and to prevent the paraffin leakage during the PCMs melting.

\subsection{Damaged PCMs}

In order to study the effect of PCMs deterioration on their thermodynamic properties, some capsules were intentionally 
subjected to damage in laboratory. Placed between two glass slides, PCMs were sheared manually by moving the slides in order to simulate the shear forces of the mixing process. After, the damaged capsules were observed by Scanning Electron Microscopy (SEM ZEISS Supra 40 VP) in the same conditions than the non-damaged PCMs.

\subsection{Measurements of DSC heat flux and specific heat}

The Differential Scanning Calorimeter (DSC) technique was used for the thermal characterization of both damaged and nondamaged PCMs. The DSC technique is useful for the determination of several thermodynamic properties of a material such as the melting and freezing temperatures, the specific heat, the phase change enthalpies etc. In this study, the experiments were performed using a DSC 204 F1 Phoenix from Netzsch under a nitrogen atmosphere by considering different masses and dynamic rates. Typical heating rates of about $5-10 \mathrm{~K} / \mathrm{min}$ are often used in standard calorimetric methods. However, it shall be pointed out that these rates could not be compatible with PCMs due to their low thermal conductivity.

Accordingly, in order to optimize the experimental parameters governing the DSC test, many investigations were performed using various dynamic rates and sample masses. For the first series of experiments, the mass was maintained constant $(12 \mathrm{mg})$ and several dynamic rates ranging between 0.5 and $20 \mathrm{~K} / \mathrm{min}$ were tested. Whereas, in the second series of experiments, the dynamic rate was kept constant $(0.5 \mathrm{~K} / \mathrm{min})$ and three different sample masses were tested ( $8 \mathrm{mg}, 10 \mathrm{mg}$ and $12 \mathrm{mg}$ ). For the two experimental configurations, three tests were performed and the average result is considered. The temperature ranges considered for this study were chosen such as to be close to the natural climate temperatures expected in building applications.

The DSC technique allows the direct knowledge of the heat fluxes per unit mass of the material managed by the DSC machine in order to maintain the same temperature between the reference and the sample

$$
\Phi=\Phi_{r}-\Phi_{s}=k \cdot\left(T_{r}-T_{s}\right)
$$

Because of the thermal inertia of the sample being tested, $T_{s}$ is deviated from $T_{r}$. The latter is prescribed by the thermal program as

$T_{r}=T_{(t=0)}+\beta t$

Eq. (1) can be expressed in terms of the specific heats as following:

$\Phi=\beta \cdot\left(C p_{r}-C p_{s}\right)$

Where $C p_{r}$ and $C p_{s}$ denote respectively the specific heats of the total reference cell and the total sample cell.

Note that Eq. (3) is available when no thermal event occurs during the test i.e. when a thermodynamic equilibrium is reached within the sample. In the opposite case for which a phase change occurs, the heat flux is no longer constant since a higher heat flux shall be supplied or subtracted to the sample cell in order to keep it at the same temperature as the reference one.

For the measurement of the specific heat $(C p)$, three DSC tests were conducted: a measurement of the base line, the standard (sapphire) and the sample. Then the ratio method was used in order to deduce the specific heat. For further details regarding the methodology of the $C p$ measurement, the readers could consult the work of [14]. a

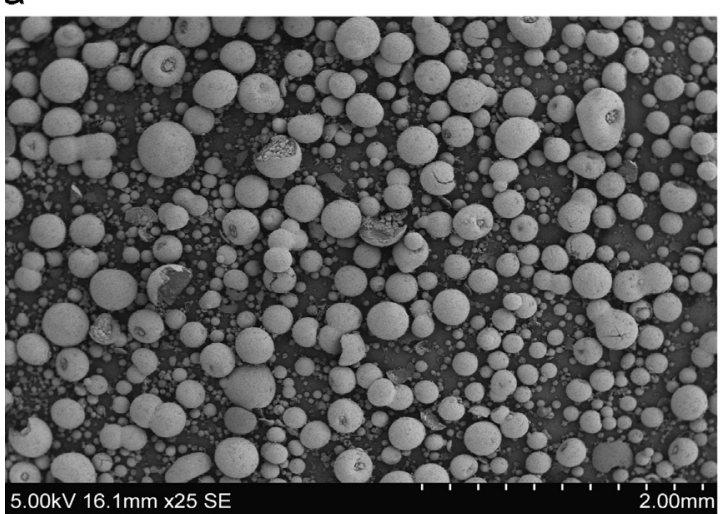

C

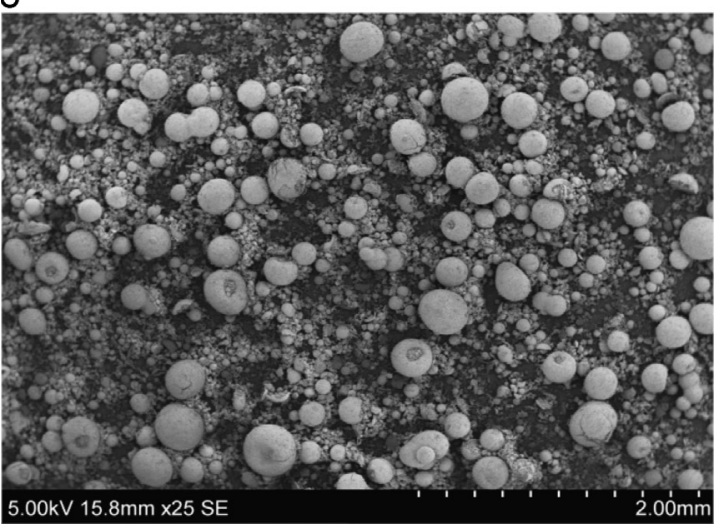

b

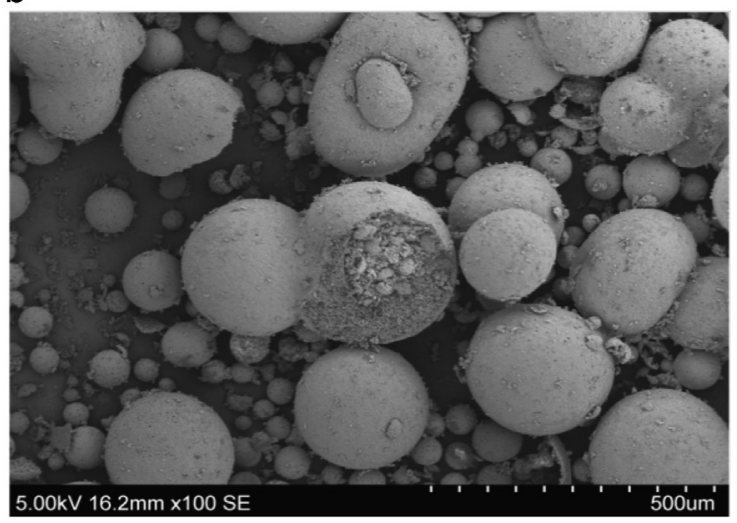

d

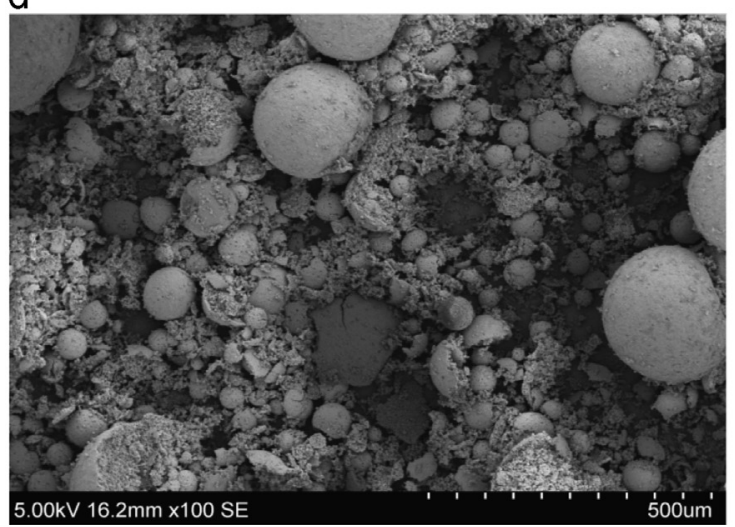

Fig. 1. SEM observations of PCMs: (a), and (b) Non-damaged PCMs (c), and (d) Damaged PCMs. 


\section{Results and discussion}

\subsection{SEM observations}

The observations of PCMs by the Scanning Electron Microscopy (SEM) technique showed the presence of macrocapsules and microcapsules of PCMs. The diameters of the macrocapsules are ranging between $50 \mu \mathrm{m}$ and $200 \mu \mathrm{m}$ and they present quite spherical agglomerates composed of many thousands of microcapsules ranging between $5 \mu \mathrm{m}$ and $10 \mu \mathrm{m}$ (Fig. 1(a), and (b)). The spherical shape appears sometimes somewhat deformed and not very smooth. In addition, it was noticed that some macrocapsules were initially damaged and even broken before their use. The damage of PCMs can be initiated by the intensified shear forces during the mixing process. It can be observed from the SEM results (Fig. 1(c), and (d)) the emergence of many fragments derived from broken PCMs as well as smaller microcapsules of diameter ranging between 5 and $10 \mu \mathrm{m}$ due to the deterioration of PCMs agglomerations after their damage.

\subsection{Heat flux, temperature peak}

The endothermic segment of the DSC signal of damaged and non-damaged PCMs, recorded at different scanning rates using the same test sample mass of $12 \mathrm{mg}$, is presented in Fig. 2. Note that in the case of damaged PCMs, the results were averaged over three new samples recovered from the same lot of PCMs subjected to the damage phenomenon. The results tests have shown a good repeatability for both damaged and non-damaged PCMs. The experimental dispersion of DSC measurements was less than $1 \%$. The average result over the different repeated tests is presented here. Note that the minus sign in the DSC values is related to the nomenclature of the International Confederation for Thermal Analysis and Calorimetry (ICTAC) often used in the thermal analysis.

One can notice that for the heating rates lower than $5 \mathrm{~K} / \mathrm{min}$, the DSC curves for both damaged and non-damaged PCMs are confused in the considered temperature range. However, when the heating rate is higher than $5 \mathrm{~K} / \mathrm{min}$, a slight difference is noticed in the heat fluxes between damaged and non-damaged PCMs cases. For illustration, a maximal deviation of $8.8 \%$ is recorded in the peak temperature at the heating rate of $20 \mathrm{~K} / \mathrm{min}$ between damaged and non-damaged PCMs.

In addition, one can see that the peak related to the PCMs phase change shifts to the higher temperatures when the heating rate increases. This finding reflects the dependence relationship of this parameter with the experimental configuration: the higher is the heating rate, the larger is the melting peak $\Delta T_{\text {peak }}$. On the

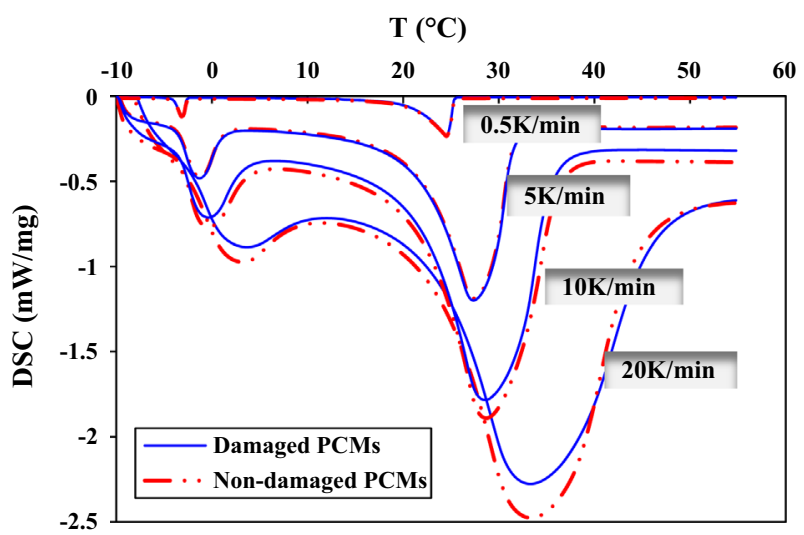

Fig. 2. Evolution of the heat flux vs. temperature for both damaged (continuous blue line) and non-damaged (dashed red line) PCMs. Mass $=12 \mathrm{mg}$.

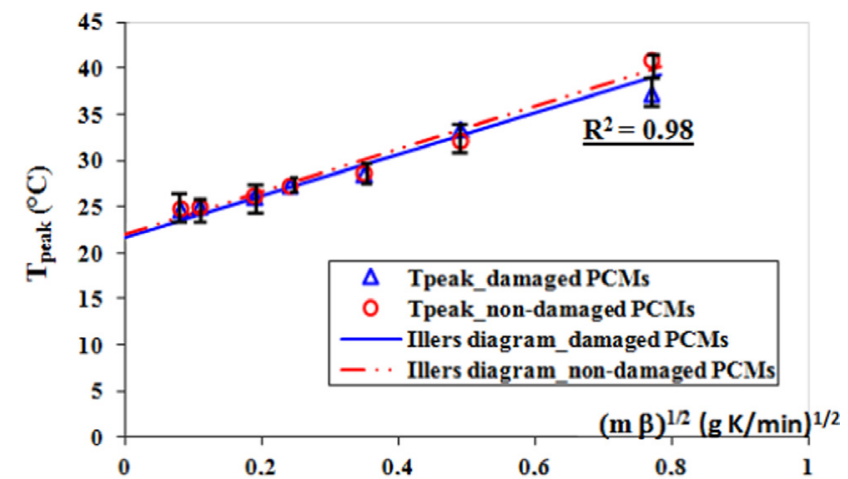

Fig. 3. Evolution of the peak temperature $T_{\text {peak }}$ vs. scanning rate for both damaged (blue) and non-damaged (red) PCMs. Mass $=12 \mathrm{mg}$

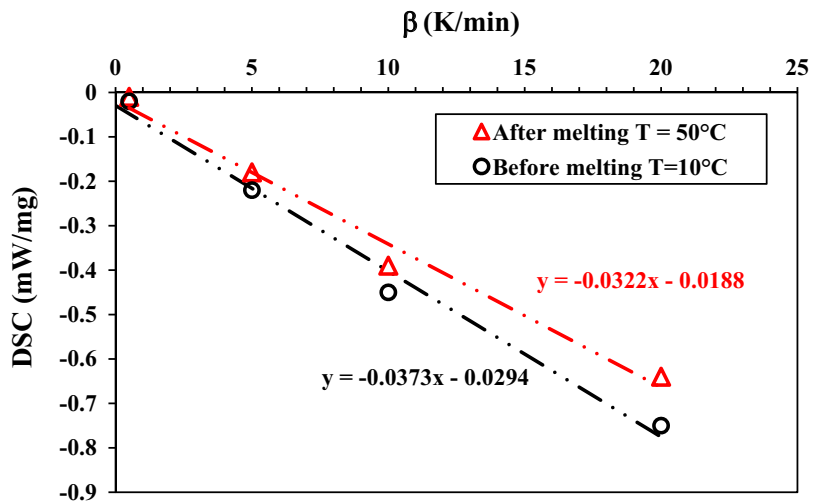

Fig. 4. Evolution of the heat flux of non-damaged PCM vs. scanning rates: before melting at $T=10^{\circ} \mathrm{C}$ (black circle) and after melting at $T=50{ }^{\circ} \mathrm{C}$ (red triangle). Mass $=12 \mathrm{mg}$

contrary, the starting melting temperature $T_{0}$, called also the "Onset" is not affected by the scanning rate since this parameter is a thermodynamic property inherent to the material and thereby, independent of the experimental conditions. To gain a better insight of the dependence of the PCMs melting peak on the scanning rate, the peak temperature evolution is plotted in Fig. 3 with respect to the heating rate for both damaged and nondamaged PCMs. One can see that the peak increases quite proportionally with the heating rate. The intersection of the tendency curves with the temperature vertical axis can be approximated to the starting melting point (onset). The extrapolated temperatures at $\beta=0$ are $21.7^{\circ} \mathrm{C}$ and $22^{\circ} \mathrm{C}$ recorded respectively for damaged and non-damaged PCMs. This means that when the scanning rate is very slow (nearly zero), the peak temperature tends to the onset. Note that this finding correlates well with the results of [22] in which a relationship was established to highlight the DSC kinetic effect on the peak temperature

$T_{\text {peak }}=T_{0}+\sqrt{2 R_{f} \Delta H} \sqrt{m \beta}$

\subsection{Specific heat of the non-damaged PCMs-determination of the} experimental parameters

\subsection{1. "Fast" approach: DSC exploitation}

In Fig. 4, the heat fluxes values of non-damaged PCMs recorded at $T=10{ }^{\circ} \mathrm{C}$ and $T=50{ }^{\circ} \mathrm{C}$ with different scanning rates are presented. Linear interpolation was used for the approximation of the heat flux with respect to the heating rate beyond the phase change interval. Note that the temperatures of $10{ }^{\circ} \mathrm{C}$ and $50{ }^{\circ} \mathrm{C}$, respectively before and after the PCMs melting were considered such as 
the heat flux curves given in Fig. 2 are quite continuous and not affected by the PCMs phase change. Based on Eq. (3), the derivative of the heat flux with respect to the scanning rate allows the determination of the specific heat of the sample:

$C p=\frac{d \Phi}{d \beta}$

In this case, the specific heat of the sample can be evaluated by calculating the slope of the heat flux tendency curves beyond the phase change range. The specific heats recorded at $10{ }^{\circ} \mathrm{C}$ and $50{ }^{\circ} \mathrm{C}$ are respectively $2.22 \mathrm{~J} / \mathrm{g} \mathrm{K}$ and $1.8 \mathrm{~J} / \mathrm{g} \mathrm{K}$. In the next section, these values will be compared to the experimental results of the specific heat measurements obtained by DSC.

\subsubsection{Experimental approach: kinetic and mass effects}

Fig. 5 presents the evolution of the specific heat capacity of non-damaged PCMs during the endothermic process in the temperature range $-10{ }^{\circ} \mathrm{C}-55^{\circ} \mathrm{C}$ with variable dynamic rates $(0.5 ; 5$; 20 ) and a constant sample mass (12 $\mathrm{mg}$ ).

It can be noticed from Fig. 5 that the heating kinetic affects the specific heat evolutions. In fact, the peak melting temperature is shifted towards higher temperatures while the phase change peak becomes larger when the heating rate in increased. This finding can be explained by the increasing of the thermal gradient within the sample and the reduction of the time necessary for the material's transformation. Furthermore, given the low thermal conductivity of PCMs (about $0.18 \mathrm{~W} / \mathrm{m} \mathrm{K} \mathrm{[14]),} \mathrm{the} \mathrm{sample} \mathrm{needs}$ more time to reach the isothermal equilibrium state and therefore more absorbed energy to achieve the phase change. Accordingly, a slow scanning rate is needed in order to allow a faithful scanning of the material with the higher resolution while ensuring the thermal equilibrium condition within the sample [21]. In addition, using small scan rates is coherent with the slow ambient rates expected in buildings applications. Note that DSC measurements with rates lower than $0.5 \mathrm{~K} / \mathrm{min}$ were not possible since the signalto-noise ratio is reduced.

Table 1 presents the specific heat values measured experimentally with different scanning rates in comparison with the values of specific heat determined according to the aforementioned method of Section 3.3.1 (Eq. (5)). $C p^{10}$ and $C p^{50}$ denote the specific heats recorded respectively at $T=10{ }^{\circ} \mathrm{C}$ and $T=50{ }^{\circ} \mathrm{C}$. Note that only a deviation less than $1 \%$ is noticed between the experiment and the suggested method for $\beta=0.5 \mathrm{~K} / \mathrm{min}$ at $T=10^{\circ} \mathrm{C}$. However, the discrepancies between the two methods are more important for higher scanning rates. A deviation of nearly $18 \%$ is recorded for $\beta=10 \mathrm{~K} / \mathrm{min}$ at $T=50^{\circ} \mathrm{C}$, for instance. This finding let deduce that the derivative method suggested for the determination of the specific heat directly from the DSC signal is more suitable and

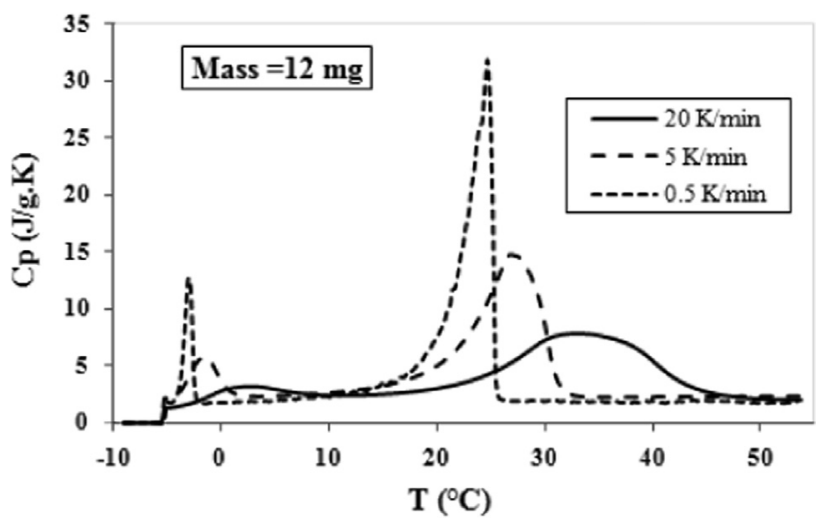

Fig. 5. Evolution of the specific heat vs. temperature, constant mass and variable scanning rates (Case of non-damaged PCMs). Mass $=12 \mathrm{mg}$.
Table 1

Specific heats of non-damaged PCMs, recorded at $T=10^{\circ} \mathrm{C}$ and $T=50{ }^{\circ} \mathrm{C}$ for different scanning rates (Mass $=12 \mathrm{mg}$ ), comparison with the "fast" approach.

\begin{tabular}{llll}
\hline & \multicolumn{1}{l}{$\boldsymbol{\beta}(\mathbf{K} / \mathbf{m i n})$} & \\
\cline { 2 - 4 } & $\mathbf{0 . 5}$ & $\mathbf{5}$ & $\mathbf{1 0}$ \\
\hline $\boldsymbol{C p}^{\mathbf{1 0}}(\mathbf{J} / \mathbf{g ~ K})$ & $2.22 \pm 0.02$ & $2.64 \pm 0.08$ & $2.69 \pm 0.1$ \\
Deviation (\%) & 0.90 & 15.20 & 16.73 \\
$\boldsymbol{C p}^{\mathbf{5 0}}(\mathbf{J} / \mathbf{g ~ K})$ & $1.80 \pm 0.03$ & $2.29 \pm 0.06$ & $2.36 \pm 0.09$ \\
Deviation (\%) & 7.22 & 15.72 & 18.22 \\
\hline
\end{tabular}

Table 2

Specific heats and melting enthalpies of non-damaged PCMs (Kinetic effect, mass $=12 \mathrm{mg})$

\begin{tabular}{|c|c|c|c|}
\hline & \multicolumn{3}{|l|}{$\beta(\mathbf{K} / \mathbf{m i n})$} \\
\hline & 0.5 & 5 & 20 \\
\hline$C p^{s}(\mathrm{~kJ} / \mathrm{kg} \mathrm{k})$ & $1.8 \pm 0.02$ & $2.3 \pm 0.05$ & $2.4 \pm 0.08$ \\
\hline Deviation (\%) & 27 & 33 & \\
\hline$C p^{1}(\mathrm{~kJ} / \mathrm{kg} \mathrm{k})$ & $1.9 \pm 0.01$ & $2.2 \pm 0.08$ & $2.0 \pm 0.07$ \\
\hline Deviation (\%) & 16 & 5 & \\
\hline$\Delta H^{m}(\mathbf{k ~ J / k g )}$ & $102 \pm 0.03$ & $96.5 \pm 0.07$ & $84.6 \pm 0.09$ \\
\hline Deviation (\%) & 9.5 & 20.7 & \\
\hline
\end{tabular}

compatible for slow scanning rates. This means that one can simply have a fast and good approximate value of the specific heat only by the knowledge of the heat flux at some low dynamic rates avoiding by this way to follow the much-time consuming conventional method for the specific heat measurement.

In the following, the specific heat average at solid and liquid states, respectively denoted $C p^{s}$ and $C p^{1}$ and the melting enthalpies $\Delta H^{m}$ are recorded in Table 2 . The deviation given here is computed with respect to the lower heating rate of $0.5 \mathrm{~K} / \mathrm{min}$.

It can be noticed from the results of Table 2 that the specific heats before and after the phase change are very close for a given scanning rate. The phase change enthalpy was classically obtained by the computation of the $C p$ peak area delimited by the $C p$ curve and the base line defined by the sensible heat. Note that the value of $102 \mathrm{~kJ} / \mathrm{kg}$ obtained with the lowest heating rate $(\beta=0.5 \mathrm{~K} / \mathrm{min})$ presents the best approximation with regards to the melting enthalpy value of $100 \mathrm{~kJ} / \mathrm{kg}$ given by the manufacturer.

Fig. 6 shows the specific heat of the PCMs measured with variable sample masses ( $8 \mathrm{mg}, 10 \mathrm{mg}$ and $12 \mathrm{mg}$ ) and a constant heating rate $(0.5 \mathrm{~K} / \mathrm{min})$. The similar trends are observed in the three curves. The results of specific heats at solid and liquid states as well as the phase change enthalpies are summarized in Table 3.

It can be pointed out that the sample mass influences the specific heats of PCMs analogically to the heating rate which let suppose a kind of equivalence between the mass and heating rate effects. It would be thought that by considering a small amount of PCMs, the temperature homogeneity and the steady state would be quickly and better reached. Nevertheless, it was noticed that testing small masses of PCMs ( $m<8 \mathrm{mg}$ ) could raise a problem since the signal-to-noise ratio becomes weaker which makes the DSC signal undetectable by the machine. In our case, a melting enthalpy of about $90 \mathrm{~kJ} / \mathrm{kg}$ was recorded with a mass of $8 \mathrm{mg}$ versus $102 \mathrm{~kJ} / \mathrm{kg}$ obtained by considering a sample mass of $12 \mathrm{mg}$. A deviation of $10 \%$ is noticed between the melting enthalpy given by the manufacturer and the one obtained by considering a small mass of $8 \mathrm{mg}$. In addition, based upon previous research works, one can notice that masses higher than $12 \mathrm{mg}$ can be used for PCMs measurements [21]. In the light of the above, the best combination retained for the DSC measurements of PCMs is $(m=12 \mathrm{mg}, \beta=0.5 \mathrm{~K} / \mathrm{min}$ ). 


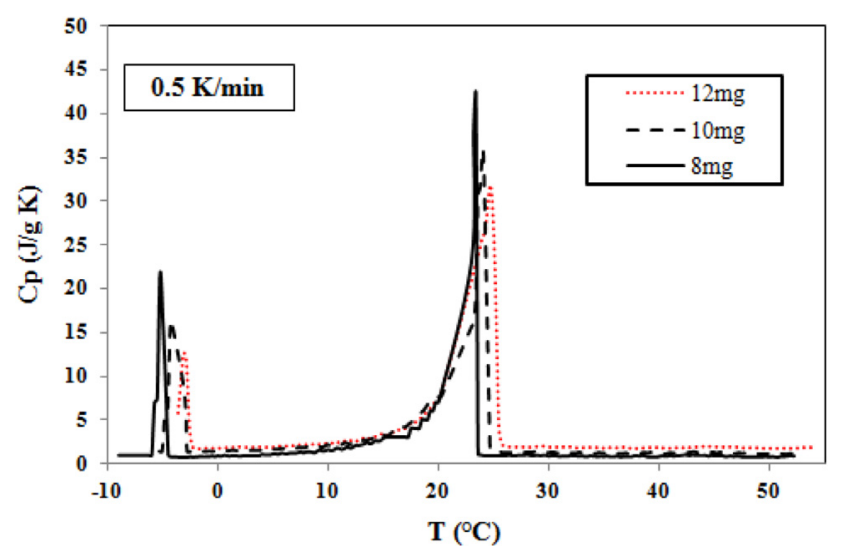

Fig. 6. Evolution of the specific heat vs. temperature, constant scanning rate. $\beta=0.5 \mathrm{~K} / \mathrm{min}$.

Table 3

Specific heats and melting enthalpies of non-damaged PCMs (Mass effect, $\beta=0.5 \mathrm{~K} / \mathrm{min}$ ).

\begin{tabular}{|c|c|c|c|}
\hline & \multicolumn{3}{|l|}{ Mass (mg) } \\
\hline & 8 & 10 & 12 \\
\hline$C p^{s}(\mathbf{k J} / \mathbf{k g ~ k})$ & $1.1 \pm 0.04$ & $1.2 \pm 0.02$ & $1.8 \pm 0.01$ \\
\hline$C p^{1}(\mathrm{~kJ} / \mathrm{kg} \mathrm{k})$ & $1.1 \pm 0.08$ & $1.1 \pm 0.06$ & $1.9 \pm 0.01$ \\
\hline$\Delta H^{m}(\mathrm{~kJ} / \mathrm{kg})$ & $89 \pm 0.09$ & $92 \pm 0.07$ & $102 \pm 0.02$ \\
\hline
\end{tabular}

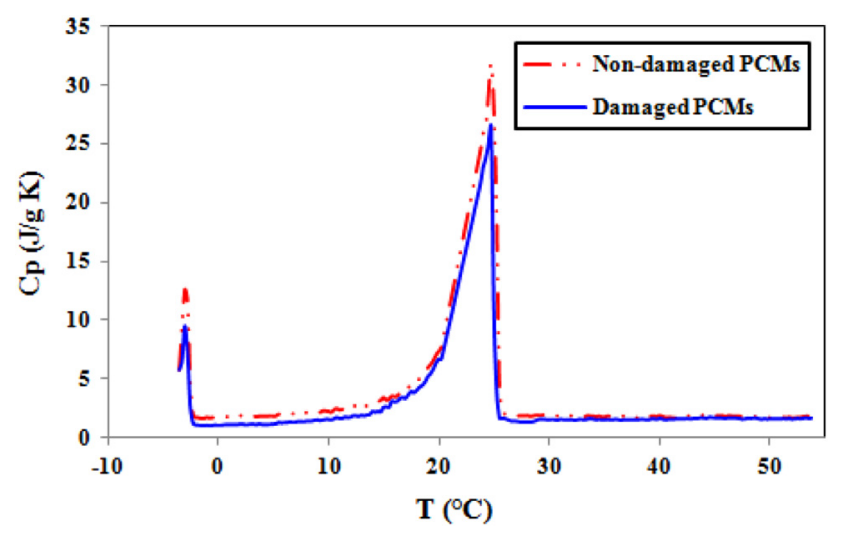

Fig. 7. Specific heats: comparison between damaged and non-damaged PCMs. $\beta=0.5 \mathrm{~K} / \mathrm{min}$, mass $=12 \mathrm{mg}$.

\subsection{Effect of damaging on the thermal properties}

The plots of Fig. 7 present the evolution of the specific heat of non-damaged PCMs in comparison with the damaged ones. One can see that in the two configurations, the $C p$ tendencies are quite the same, namely the damage of PCMs would have not influenced the evolution of the specific heat versus the temperature. However, if we take a look at the quantitative analysis of the specific heats values recorded in Table 4, one can see that the damaged PCMs exhibit lower heat capacities than the reference ones. A deviation of nearly $28 \%$ between the damaged and non-damaged case is recorded in the estimation of the heat capacity of PCMs before their melting. This result could be explained by the leakage of the paraffin active compound from the capsules after the damage of PCMs, for example and/or the deterioration of the thermal transfer conditions due to the rupture of the shell exchange surfaces which could be relevant to preserve the properties of PCMs and to ensure their stability from a thermal point of
Table 4

Comparison damaged and non-damaged cases $(\beta=0.5 \mathrm{~K} / \mathrm{min}$, mass $=12 \mathrm{mg}$ ). Deviation of the damaged PCMs compared to the non-damaged PCMs.

\begin{tabular}{llll}
\hline & $\boldsymbol{C p}^{\boldsymbol{s}}(\mathbf{k J} / \mathbf{k g ~ k})$ & $\boldsymbol{\Delta} \boldsymbol{H}^{\boldsymbol{m}}(\mathbf{k J} / \mathbf{k g})$ & $\boldsymbol{C p}^{\mathbf{1}}(\mathbf{k J} / \mathbf{k g ~ k})$ \\
\hline Damaged PCMs & $1.29 \pm 0.05$ & $90 \pm 0.02$ & $1.59 \pm 0.38$ \\
Non-damaged PCMs & $1.8 \pm 0.18$ & $102 \pm 0.01$ & $1.9 \pm 0.06$ \\
Deviation (\%) & 28 & 12 & 16 \\
\hline
\end{tabular}

view. It shall be emphasized that the thermal response of the PCM samples is strongly dependent on the wax paraffin component and that the contribution of the polymer shell is negligible because of its small mass proportion in PCM, on the one hand and its lower specific heat with regards to the wax on the other hand. This finding highlights the damage effect of PCMs and the importance to take it into account to faithfully estimate the PCMs thermal properties. From an operational point of view, this means that by introducing the PCMs at the first stage of the mixing process during the manufacture of the PCM-material, a loss in the energy storage, gained both by sensible and latent heats of PCMs, could be attained. Accordingly, the thermal inertia of the PCM-material composite is deteriorated and the energy efficiency target is not really achieved. Thus, it shall be emphasized that the processing of the PCM-material shall be carefully planned and optimized.

\section{Limitations}

Some highlights are presented in this study but several limitations can be noticed. To begin with, the signal-to-noise ratio makes difficult to perform DSC measurements with very small samples masses and very low scanning rates. Measurements with mass and dynamic rate lower than $8 \mathrm{mg}$ and $0.5 \mathrm{~K} / \mathrm{min}$ respectively were practically impossible. The measurement accuracy can be lost in these cases on the one hand, and the DSC tests are too much time and energy-consuming on the other hand.

In addition, it could be questioned the damage level of PCMs used in this study. Note that the PCMs tested herein were severely damaged in order to better simulate the in-situ damage scenario to which PCMs can be subjected when introduced at the beginning of the concrete mixing process. Nevertheless, it shall be emphasized that even though PCMs were incorporated at the final mixing operation, the deterioration of some capsules could not be avoided but the damage level is lower. Accordingly, it would be of interest to further investigate this aspect in order to establish in the future predicative relations allowing the determination of the thermal performances of PCMs with respect to the damage scenarios or levels which could result from the manufacture process of the PCM-mixture.

Although the thermal aspect was only investigated in this paper, it appears also necessary to study the mechanical behavior of the PCM-material. What could be the effect of PCM damage on the mechanical properties of the PCM-material? Would the leakage of paraffin and its potential interaction with the surrounding matrix affect the mechanical strength, for instance? Research works are now in progress to further analyze the thermo-hydromechanical behavior of the PCM composite for a better understanding of their energy efficiency potential.

\section{Conclusions}

In this study, experimental parameters for the PCMs testing were optimized through a DSC thermal investigation of their properties. It was shown in this framework a "fast" approach 
allowing a good approximation of the specific heats by the direct exploitation of the DSC heat flux curve. This method based on the derivation of the DSC signal assumes that a steady state and a thermal homogeneity are reached in the sample. For this purpose, both scanning rate and sample mass have to be well controlled to faithfully reproduce the thermal characteristics of the material. In addition, in order to evaluate the potential deterioration of PCMs which could occur during the PCM-concrete manufacture (by mixing, for example), a comparison was presented between damaged and non-damaged PCMs on the basis of their thermal properties. It was highlighted through this study that the damage of PCMs can exhibit negative effects on the thermal storage capacity of PCMs and therefore the overall modified composite. Losses of $28 \%$ and $16 \%$ were recorded in the specific heats of PCMs, respectively in solid and liquid states. Accordingly, an overestimation of the thermal efficiency of PCMs can be made if the materials damage is not taken into account. This work opens promising paths and prospects to: (i) further investigate the damage of PCMs from a quantitative and qualitative point of view with regards to the PCM-mixture manufacture, (ii) better understand the thermal behavior and long-term efficiency of damaged PCMs, on the one hand and their effective contribution for the enhancement of the thermal energy storage capacity of the PCM-concrete on the other one.

\section{Acknowledgment}

The authors would like to thank BASF-The Chemical Company of Germany for their supply of PCMs material as well as the laboratory of ENPC-NAVIER (France) for their experimental assistance in conducting the SEM tests.

\section{References}

[1] L. Pérez-Lombard, J. Ortiz, C. Pout, A review on buildings energy consumption information, Energy Build. 40 (3) (2008) 394-398.

[2] H. Mehling, L.F. Cabeza, Heat and Cold Storage with PCM: An Up to Date Introduction into Basics and Applications, Heat and Mass Transfer, Springer 2008.

[3] M.M. Farid, A.M. Khudhair, S.A.K. Razack, S. Al-Hallaj, A review on phase change energy storage: materials and applications, Energy Convers. Manag. 45 (2004) 1597-1615.

[4] A. Sharma, et al., Review on thermal energy storage with Phase Change Materials and applications, Renew. Sustain. Energy Rev. 13 (2009) 318-345.
[5] N. Soares, J.J. Costa, A.R. Gaspar, P. Santos, Review of passive PCM latent heat thermal energy storage systems towards buildings' energy efficiency, Energy Build. 59 (2013) 82-103.

[6] D.W. Hawes, D. Banu, D. Feldman, The stability of Phase Change Materials in concrete, Sol. Energy Mater. Sol. Cells 27 (1992) 103-118.

[7] L.F. Cabeza, C. Castellon, M. Nogues, M. Medrano, R. Leppers, O. Zubillaga, Use of microencapsulated PCM in concrete walls for energy savings, Energy Build. 39 (2007) 113-119.

8] H. Zhang, O. Xu, Z. Zhao, J. Zhang, et al., Preparation and thermal performance of gypsum boards incorporated with microencapsulated Phase Change Materials for thermal regulation, Sol. Energy Mater. Sol. Cells 102 (2012) 93-102.

[9] A. Pasupathy, R. Velraj, R.V. Seeniraj, Phase change material based building architecture for thermal management in residential and commercial establishments, Renew. Sustain. Energy Rev. 12 (2008) 39-64.

[10] V.V. Tyagi, S.C. Kaushik, S.K. Tyagi, T. Akiyama, Development of Phase Change Materials based microencapsulated technology for buildings: a review, Renew. Sustain. Energy Rev. 15 (2011) 1373-1391.

[11] M. Delgado, A. Lazaro, J. Mazo, B. Zalba, Review on phase change material emulsion and microencapsulated phase change materiel slurries: materials, heat transfer studies and applications, Renew. Sustain. Energy Rev. 16 (2012) 253-273.

[12] P. Meshgin, Y. Xi, Effect of Phase-Change Materials on properties of concrete, ACI Mater. J. 109 (2012) 71-80.

[13] M. Hunger, A.G. Entrop, I. Mandilaras, H.J.H. Brouwers, M. Founti, The behavior of self-compacting concrete containing micro-encapsulated Phase Change Materials, Cem. Concr. Compos. 31 (2009) 731-743.

[14] A. Eddhahak, S. Drissi, J. Colin, J. Neji, S. Care, Experimental and multi-scale analysis of the thermal properties of Portland cement concretes embedded with microencapsulated Phase Change Materials (PCMs), Appl. Therm. Eng. 64 (2013) 32-39.

[15] A. Eddhahak, S. Drissi, J. Colin, S. Caré, J. Neji, Effect of Phase Change Materials on the hydration reaction and kinetic of PCM-mortars, J. Therm. Anal. Calorim. 17 (2014) 537-545.

[16] H. Mehling, H.P. Ebert, P. Schossig, Development of standards for materials testing and quality control of PCM, in: Proceedings of the 7th IIR Conference on Phase Change Materials and Slurries for Refrigeration and Air Conditioning, 2006.

[17] E. Günther, S. Hiebler, H. Mehling, R. Redlich, Enthalpy of Phase Change Materials as a function of temperature: required accuracy and suitable measurement methods, Int. J. Thermophys. 30 (2009) 1257-1269.

[18] J.M. Marín, B. Zalba, L.F. Cabeza, H. Mehling, Determination of enthalpy temperature curves of Phase Change Materials with the T-history methodimprovement to temperature dependent properties, Meas. Sci. Technol. 14 (2003) 184-189.

[19] C. Castellón, E. Günther, H. Mehling, S. Hiebler, L.F. Cabeza, Determination of the enthalpy of PCM as a function of temperature using a heat-flux DSC-a study of different measurement procedures and their accuracy, Int. J. Energy Res. 32 (2008) 1258-1265.

[20] X. Jin, X. Xu, X. Zhang, Y. Yin, Determination of the PCM melting temperature range using DSC, Thermochim. Acta 595 (2014) 17-21.

[21] C. Barreneche, A. Solé, L. Miró, I. Martorell, A. Inès Fernández, L.F. Cabeza, Study on differential scanning calorimetry analysis with two operation modes and organic and inorganic phase change material (PCM), Thermochim. Acta 553 (2013) 23-26.

[22] K.H. Illers, The determination of the melting point of the crystalline polymer by Calorimetry (DSC), Eur. Polym. J. 10 (1974) 911-916. 